\title{
How to use analogies for breakthrough innovations
}

Dipl. Wi.-Ing. Katharina Schild

Prof. Dr. Cornelius Herstatt

Dr. Christian Lüthje

Mai 2004

Arbeitspapier Nr. 24 


\title{
How to use analogies for breakthrough innovations
}

\section{Katharina Schild $^{1}$, Cornelius Herstatt ${ }^{2}$ and Christian Lüthje ${ }^{3}$}

\author{
${ }^{1}$ schild@tu-harburg.de \\ ${ }^{2}$ c.herstatt@tu-harburg.de \\ ${ }^{3}$ luethje@tu-harburg.de \\ All at the Institute of Technology and Innovation Management, Technical University of Hamburg, \\ Schwarzenbergstrasse 95, 21073 Hamburg, Germany
}

\begin{abstract}
Analogies can trigger breakthrough ideas in new product development. Numerous examples demonstrate that substantial innovations often result from transferring problem solutions from one industry or domain to another. For instance, the designers of the new running shoe generation of Nike, "Nike SHOX", use the same suspension concept like the technologies applied for Formula 1 racing cars, or the biological Lotus-effect led to the development of various self-cleaning surfaces.

Academic research on analogical thinking has been so far heavily influenced by general theoretical work from cognitive psychology or systematic inventing. Only a small number of studies have investigated the application of analogies in the specific context of breakthrough innovation projects. This paper focuses on the question how analogies can be systematically used in the early innovation phases of new product development and which factors influence the successful use of analogical thinking in innovating companies. Special attention is paid to organizational facilitators and the requests on people involved in this process.
\end{abstract}

\section{Introduction}

Creating breakthrough innovations is a key strategy for many companies in an increasingly tight competition. A breakthrough innovation is a substantial innovation - a vital improvement in an existing system (Terninko, 1998).

An important precondition for the development of substantially new products is the identification of breakthrough ideas for problem solutions in the front end of the innovation process. A new and creative solution usually results from the fusion of pieces of knowledge that have not been connected before. (Geschka and Reibnitz, 1983) Therefore breakthrough innovations often have evolutionary origins - e.g. the steamship as a combination of a steam-engine with a sailing boat. Although an innovation can be based on a new scientific or technical discovery, the recombining nature of innovations is more dominant. (Hargadon, 2002; 2003)

Combining existing knowledge in a novel way in order to develop a breakthrough product is not trivial. According to the theory of bounded rationality the searchfield of a developer - the same as any other individual - is constrained. He/she, when developing solutions, is only able to notice a limited section of the environment, because of his/her limited cognitive abilities. (Simon, 1957; 1982; 1996) In addition, the retrieval of solutions from very distant domains can be constrained by established thinking patterns. Most people search for solutions in the nearer context of the problem as they are led by already fixed thinking structures. Especially innovations with a high degree of newness can be constrained by learned and inherited schemata. ${ }^{1}$ And functional fixedness based on experiences of former projects can block the way to innovative solutions. (Birch and Rabinowitz, 1951) Besides, most people have difficulties to think outside of their area of original expertise, because this usually requires them to use a different way of thinking and a different technical language than they are used to. 
(Terninko et al., 1998)

A fundamental cognitive mechanism to retrieve existing knowledge and to apply this knowledge to new problems is an analogy - "a statement about how objects, persons, or situations are similar in process or relationship to one another". (VanGundy 1981, p.45) A wide variety of analogy-forms exists. On the one hand, for example, an automotive company that operates in the high end market can try to transfer a customer-experience of luxury from fashion boutiques or hotels to the services concerning its products. On the other hand, an existing technology can be transferred to a new product. In this paper we focus mainly on product innovation and analogies used to recombine and transfer technologies in combination with breakthrough innovation.

This paper focuses on the question how analogies can be systematically used in the front end of new product development and which factors influence the successful use of analogical thinking in innovating companies. Special attention is paid to organizational facilitators and the requests on people involved in this process.

The paper is organized as following: We start discussing the nature of analogies. The recognition of analogies as a fundamental attribute of human cognition is explained considering different types of analogies, such as, for example, near and far analogies.

We then discuss existing approaches to implement the idea of analogical thinking to create breakthrough ideas. More specifically, we look at synectics, TRIZ, bionics, and the lead user approach. These methods are evaluated according to their applicability and limitations. Based on this, we propose a systematic procedure which intends to support designers in retrieving, evaluating and using analogies in the context of innovation projects. This general proceeding is illustrated with insights from a recent project in a leading medical equipment company.

Finally, we explore organizational conditions fostering the retrieval and application of analogies in new product development. As a result, we develop a number of propositions on organizational mechanisms to achieve an effective use of analogical thinking within the context of breakthrough innovation projects.

\section{The nature of analogies}

"The ability to perceive similarities and analogies is one of the most fundamental aspects of human cognition. It is crucial for recognition, classification, and learning and it plays an important role in scientific discovery and creativity." (Vosniadou, 1989, p. 1)

In cognitive psychology analogies are used to describe and partially explain the nature of problem solving. (Gick and Holyoak, 1980) It is assumed that a novel problem (= target problem) can be solved with the help of an already existing solution of an analogue problem (= base analogue). Two basic stages in this process of analogical transfer are the retrieval of a base analogue and the mapping of knowledge from the base domain into the target domain. In order to explain this process cognitive psychology differentiates between surface similarities and structural similarities. Surface similarity describes the resemblance of target-objects to base-objects. Structural similarity exists if relations between elements of the base object are similar to relations between various elements of the target object. Structural similarity is important for a correct application of the analogy and its evaluation. (Blanchette and Dunbar, 2000; Gentner, 1989; Holyoak and Thagard, 1995; Keane, 1988; Reeves and Weisberg, 1994)

The creativity potential of an analogy depends on the dissimilitude of the knowledge bases between which the analogy is drawn. A near analogy is an analogy from a closely related base domain, for example if the cushioning of a new running shoe is developed analogue to existing cushioning concepts already used for other running shoes. On the opposite, an analogy is meant to be far if it comes from a distant domain, for example if the cushioning of a new running shoe is developed analogue to suspension-technologies, for example in racing cars. ${ }^{2}$ As far analogies seem to have a greater potential to enhance creativity compared to near analogies, breakthrough innovations are more likely to result from far analogies between distant domains. (Dahl and Moreau, 2002; Reeves and Weisberg, 1994; VanGundy, 1981)

A key problem in using analogies for problem solving in innovation projects is to find relevant analogies early in the process. As analogies can only be accessed if relevant knowledge of the base domain is available to an innovating person or group, one difficulty in accessing analogies is missing this specific knowledge in the context of the base domain. In addition, even if relevant knowledge is available problems often just do not get solved, because innovating persons do not realize that their existing knowledge is relevant in this current context. (Hargadon, 2003; Gick and Holyoak, 1980) Especially far analogies are hard to retrieve, because they usually lack surface similarities that would facilitate their retrieval. The transfer of far analogies happens on a more abstract level than the transfer of near analogies and depends strongly on structural similarities (Gentner, 1989; Dahl and Moreau, 2002; Reeves and Weisberg, 1994). Besides, the retrieval of far analogies is complicated since learning is contextual the knowledge is linked with the situation and meaning in which it is learned. (Gick and Holyoak, 1980) In this sense, finding relevant distant analogies is a complex search problem. Johnson-Laird (1989) argues that a traceable algorithm that guarantees success for such a search cannot exist. Perkins (1992) describes this kind of search space as a "Klondike space" in which there is no target gradient leading to a solution.

It seems likely that the use of analogies in the innovation process depends on the existing knowledge of the involved persons. Unknown solutions are less likely to be found. Besides, even the detection of analogue solutions from known domains is often an accidental act. In this sense analogies seem to just appear out of the unconscious - a sudden, not expected insight. Waiting for 
such enlightenment, however, is not satisfying for any company that aims for generating breakthrough innovation. In the following section existing approaches that use analogies to create innovative solutions are presented.

\section{Existing approaches incorporating the idea of analogical thinking}

Several procedures and methods exist which can be used to generate innovative ideas for product concepts based on analogies. Such methods include synectics, the lead user approach, TRIZ and bionics.

These approaches and methods can be distinguished with respect to their systematics concerning the depth and width of analogy-search. Besides, they differ in respect to the formality of their procedure (see table 1). A search for analogies is deep if a defined search space is thoroughly explored. The width of a search for analogies describes if there are restrictions concerning the type and number of knowledge fields that can be entered.

Synectics is a creativity method and relies on the knowledge and ideas of the participants. The lead user approach activates the knowledge and ideas of a certain subgroup of users. As both methods rely on the knowledge of individuals, their depth of search is low. However, in both approaches analogies can be drawn from any field. Therefore their width of search is not limited. In contrast to the lead user approach, synectics follows a formal procedure.

TRIZ is based on the knowledge pool of about 2.5 Million patents. It does not depend on knowledge of individuals, but is restricted to technical solutions reflected in these patents. Therefore searching for analogies with TRIZ is deep, but limited concerning its width. Besides, it is based on a formal procedure.

In bionics analogies are drawn from nature. Different approaches to uncover the various sources of bionic knowledge exist ranging from intuitive creativity to a systematic as well as formal search for analogue solutions.

\begin{tabular}{|l|l|l|l|}
\hline \multirow{2}{*}{} & \multicolumn{2}{|c|}{ Systematics } & \multirow{2}{*}{$\begin{array}{c}\text { Formal } \\
\text { procedure }\end{array}$} \\
\cline { 2 - 3 } & Depth of search & Width of search & Yes \\
\hline Synectics & Low & Not limited & Yes \\
\hline Lead User & Low & Not limited & No \\
\hline TRIZ & Deep & $\begin{array}{l}\text { Limited to } \\
\text { TRIZ-database }\end{array}$ & Yes \\
\hline Bionics & Partially & $\begin{array}{l}\text { Limited to } \\
\text { biology }\end{array}$ & Partially \\
\hline
\end{tabular}

Table 1: Classification of methods according to systematics and formality
Synectics is a creativity technique originally developed by William Gordon (1961). By simulating the phases of incubation, illumination and verification the naturally running creative thought process gets reproduced. First, the strange should become familiar - the problem is defined and analyzed. Second, the familiar is supposed to become strange. Operational mechanisms incorporating analogies are used to pull the problem solver away from the problem and to overcome his bias. This process starts with a direct analogy to the problem. This analogy is received by free association of the participants and can be drawn from areas as nature, technology, history, politics, mythology, art and others. Especially biological organisms provide a rich source for direct analogies to technical problems. (VanGundy, 1981) If one does not want to rely on free associations of the participants, the group leader can prepare a number of analogies in advance. One of the generated analogies is then chosen by the group and to this object or idea a personal analogy is developed. Here the participants imagine themselves to become the object, thing, person or idea. A personal analogy requires involvement leading to a new experience of the object. Then, one aspect of the personal analogy is chosen to form a symbolic analogy. In a symbolic analogy objective and impersonal images are used to describe the problem. Afterwards direct analogies are again developed to the one chosen symbolic analogy.

At the end of this process the alienation is transferred back to the original problem statement ("force-fit"). Thereby the analogies are finally analyzed concerning their characteristics, attributes and functions, and partial structures of them are tested concerning their transferability to the original problem. (Gordon, 1961; VanGundy, 1981; Geschka and Reibnitz, 1983)

Synectics is a structured and much formalized creativity technique. It does not aim at finding the best fit analogy to a problem, since any suitable analogy can be chosen and further alienated in order to free ones mind and to broaden ones horizon. The core of synectics is the "force-fit" when results of the alienation process are transferred to the original problem to find a creative solution.

Advantages of a synectic session are the possibility to unlock rigid thinking patterns and the structure that it provides to the creative process. Besides, the subconscious is systematically included in the creative process. A disadvantage of a synectic session is the necessity of a trained leader for effective performance. Companies very rarely apply synectics, because they think it is too complex and difficult. (Herstatt and Geschka, 2002; Baxter, 1995) Finally, the method heavily depends on the participants - their knowledge, open-mindedness and ability to use analogies. A guideline to compose a good synectic group is to include persons with moderately diverse backgrounds concerning their work and educational experiences. (VanGundy, 1981)

\subsection{Lead User Method}

\subsection{Synectics}


concepts, because they are trapped in their experiences with existing products. However, as several studies show, a certain group of users - lead users - can be very valuable in the innovation process. Lead users are progressive users that have a high motivation to obtain a solution to their so far unmet needs. (von Hippel, 1988) Lead users can usually be found at the leading edges of the company's target market and face extreme situations. For example, an automobile manufacturer who wants to improve its breaking system can look at auto racing teams. Furthermore, this company can look at users out of the target market that face similar problems. Breaking for example plays an important role in aerospace, too, especially the military section. ${ }^{3}$ (von Hippel, 1999)

Two approaches to incorporate analogies into the lead user method exist. First, the company can look for analogue areas and involve lead users from these analogue markets into the innovation process. Users in analogue markets can not be expected to develop own ideas and concepts for the problem of the company, but they can be interviewed about the techniques they use and thus provide ideas for breakthrough products in the target market (Herstatt and Lettl, 2004).

Second, lead users from the target market can be very helpful in identifying relevant analogue search fields. As Lettl (2004) has observed in a number of case studies in the medical field, lead users often take knowledge from analogue fields to develop their product concepts. In a way, lead users are more open to analogue fields than the manufacturers of the products. As users are not necessarily experts in developing products, they are often forced to use knowledge from hobbies, previous jobexperiences or contacts with other experts. Thus, the more interdisciplinary knowledge the lead users have the higher the probability that they combine knowledge from different fields into the solution.

In order to involve lead users in the innovation process they first need to be identified. One effective approach to identify lead users involves networking. Von Hippel (1999) describes how lead users can be identified via telephone interviews asking experts to name other experts. In addition, the identified lead users from the target market can be asked to name experts in analogue fields. A developing team that focused on medical imaging identified certain radiologists as lead users. These radiologists could subsequently name specialists in pattern recognition that worked on military satellite technology. The radiologists thought these specialists were even further ahead as them concerning the development of techniques for image analysis. Lead users can also help to specify the project goal by talking about analogue experts - in the above mentioned example the focus changed from finding a way to create better high resolution images to finding methods for recognizing medically significant patterns in images. (von Hippel, 1999)
The lead user method does not follow a formal procedure and does not systematically search for analogies. If lead users are used to identify analogies the search for analogies depends on their knowledge and experiences. The method can provide useful insights especially for companies that operate at the front end of their target market, because they depend on ideas from analogue fields to further improve their products.

An advantage of the lead user method is that lead users have a thorough understanding of the problem to be solved and are usually open minded to combine knowledge from different fields. Therefore they can help to identify valuable analogue fields that are in certain aspects ahead of them and from which they expect useful insights for the products they use. Besides, the lead user method can be applied by any company; no experts or special training is needed. A disadvantage is that the identification of lead users can be difficult and time consuming.

\subsection{TRIZ}

The "Theory of Inventive Problem Solving" (TRIZ) was created by Genrich Altschuller. ${ }^{4}$ His vision was to develop a science of creativity that reduces the time to invent and structures the process enhancing breakthrough thinking. (Terninko et al., 1998)

TRIZ is based upon the idea that all technical problems already got somehow solved in the past. This knowledge can be found in patents. By now, about 2.5 million patents have been evaluated. The inherent solution principles are stored in a database. The information from the patents is condensed into 40 principles to solve technical contradictions, 4 separation principles to solve physical contradictions, 76 generic solutions and basic laws of technical evolution. (Terninko et al., 1998)

Here, we are especially interested in the analogy part of TRIZ. The specialty of TRIZ is the systematic approach to find analogue solutions: After analyzing a problem it is described on a more abstract level. This information and identified contradictions - for example to get something big through a small opening - are used to search for analogue solutions in the database.

TRIZ delivers a systematic way to find in restricted time analogue technical solutions, because the search space for analogies is limited and the search can be effectively supported by software. By using the database and general solution principles the knowledge base is expanded making the company more independent from the individual experiences and know-how of its employees. (Terninko et al., 1998)

While the use of patent database and formal rules enables a wider and more systematic search for analogical problem solutions TRIZ has some shortcomings. TRIZ can only be used for technical problems. Closely linked to this point is the restriction of the search space for analogue problem solutions to the analyzed patents in the database. Finally, the TRIZ method is complex. If a company wants to apply TRIZ using internal resources the company needs 
to provide a TRIZ-training and TRIZ-software. ${ }^{5}$

\subsection{Bionics}

In bionics ideas are gained from nature and transferred to technical problems. (Nachtigall, 1998) For example the production of paper from wood was copied from wasp's nests structures and more recently the structure of shark skin is used to reduce flow resistance. (Bappert et al., 1998) The use of analogies is a basic principle in bionics: starting with a technical function that needs to be realized, bionic-experts look in nature for systems with similar functions. If their search is successful they transfer structural attributes or sub-systems of the biological system on to the technical system that meeds to get developed. This can be performed in a systematic process (Hill, 1993):

1. Functional attributes of the technical target system are analyzed and abstracted

2. Transfer of these attributes into the biological world (here a database can be used)

3. Comparison of the functional attributes of the technical system with its biological analogy

4. Relevant analogies are chosen and prominent structures revealed

5. Creative transfer and adoption of principle structures of the system to be developed

Bionics can be used on different levels: On the one hand it can serve as an idea-stimulation tool in a creativity workshop, on the other hand, deep and long-term research in bionic solutions is performed, primarily at universities and technical research institutes.

So far, bionics is not widely used in the industrial innovation process. Research institutes that do research in bionics are often deeply specialized and not able to respond fast with appropriate answers to varying industry tasks. (Rummel, 2004) However, various approaches of an application-oriented bionics exist today. For example, one group has started to collect bionic solution principles in catalogues ${ }^{6}$ that can be used in product development. (Hill, 2004) These catalogues are neither published nor are they made available in a software solution, however one can learn basic principles of bionics through bionic textbooks.

A different approach of an application-oriented bionics is the search for analogue solutions in publicly available biological knowledge. After condensing the problem concerning basic biological principles of convergence, databases containing publications in biological research are scanned. A very important step in this method is the verification of identified solutions and deep understanding of the biological system. (Rummel, 2004) $)^{8}$ The search for bionic solutions in databases has certain similarities to TRIZ. And some approaches to include bionic solutions into the TRIZ database already exist. (Vincent and Mann, 2002). ${ }^{9}$
Bionics is an interdisciplinary approach. To apply bionics appropriately biologist with additional technical knowledge are needed as well as engineers with some biological knowledge. The knowledge of the developing team can be expanded through access to bionic catalogues and databases.

The analogies used in bionics are far analogies and therefore promise a high potential of creativity. Another advantage is that nature's solutions are not protected by patents. They can be exploited without legal restrictions. (Rummel, 2004) One main principle of biological solutions is to achieve a maximum effort with minimal resources. These over million of years optimized systems deliver valuable ideas concerning sustainable product development (Hill, 1999).

The advantage of high creativity correlates with the disadvantage that transferring bionic solutions can be difficult. A thorough understanding of the biological system is needed to identify the relevant factors. And finally, the solution search space in bionics is restricted to nature that cannot help with all technical problems.

\section{Systematic approach to retrieve, evaluate and use analogies}

A systematic approach to find analogue solutions to a given problem can consist of different phases. First, the problem needs to be analyzed. After the problem is formulated and structured, the company has to carefully reflect how promising it is to search for analogies or if other ways to trigger new product ideas and concepts are more appropriate. In the subsequent search phase, one has to decide on a general search strategy. And finally, if analogous solutions have been identified, they need to be further verified and evaluated. This outlined process is not necessarily linear, since feedback loops and repetition of activities often become unavoidable if the results do not meet expectations and pre-defined development targets.

This process of identifying analogue solutions to a given problem will be illustrated by examples from a development project which we recently conducted in combination with a leading medical equipment company. The target of this activity was to develop a next generation product for so-called hernia repair. In hernia repair, normally, devices are formed of a synthetic mesh to support weak tissue in the patient's body. Since these devices cause a variety of pre-, in- and post-surgical problems, the project targeted to identify alternative ways to operate and cure hernias.

\subsection{Problem definition}

First, the development problem needs to be defined. When analyzing and formulating the nature of a problem and the requirements to an adequate solution, one has to decide on a level of abstraction. A certain degree of abstraction is needed if a search for analogies is aspired. 
On the one hand, creativity can be restricted by a too detailed formulation of the problem. Since it may lead to a narrow search far analogies won't be considered. On the other hand, a broad and less specific problem definition opens a wide search space making the search more complex and perhaps not manageable.

To arrive at a practicable problem definition several aspects should be considered. First, general conditions that are important for the success of a solution should be identified. For example, to develop a new solution for hernia-repair it is important to thoroughly understand the anatomy of a human abdomen as well as to be aware of restrictions concerning the operation procedure.

Second, as shown with TRIZ, it can be helpful to identify contradictions that need to be solved. In hernia repair a contradiction is, for example, providing a strong support for the weak tissue and not causing pain to patients. Besides, breaking down the problem into subproblems can be conducive. Then the relations between sub-problems should be considered, too, - especially contradictions that might appear.

And third, it is important to integrate the view of the customer into the problem definition. An effective way to understand the situation of the customer provides the method of emphatic design. Observing the customer using existing products in the context where the new product is supposed to be used leads to valuable insights (Kelley, 2001; Leonard and Rayport, 1997; Squires and Byrne, 2002). In the hernia repair project, surgeons that frequently operate hernia and have to perform this in part under extreme conditions - for example with obese patients, athletes or children - were visited. They were interviewed concerning their experiences with existing hernia devices and carefully observed performing hernia operations. As one important result general demands on a new hernia device could be identified - for example it has to be easy and fast in deployment.

After arriving at a problem definition the project-team has to evaluate if the search for analogies is the right way or if other methods are more promising. In general, analogies can be used with creative problems. If a problem is well structured and can be solved by a known algorithm a search for analogies won't be appropriate.

In general, a search for analogies is recommendable when developing a breakthrough innovation, because this is altogether a creative task. Especially, if other approaches have not led to satisfying ideas a search for analogies is promising. The methods described in section 3 show that analogies can be used in varying ways. In order to decide on the most promising search strategy the project team should be aware about its available time and capacities. Time and capacity is needed to perform the search for analogies. But, time and capacity can also be saved, if an analogue solution is found.

\subsection{Search for analogies}

The starting point for the search of analogies is the knowledge of the project team. This knowledge can be activated in a brainstorming session where the team members draw analogies to past projects or experiences from hobbies, education and other areas. The activation of analogies with past projects can be fostered by displaying objects from past projects at the brainstorming session. (Hargadon 2002; 2003). Although persons can generate more ideas per time-unit when they are sitting alone and are undisturbed, brainstorming in a group is effective because of social interactions. (Sutton and Hargadon, 1996) A diverse background of the team members enriches the knowledge from which analogies can be drawn. For example, the hernia repair development team contained material experts, physicians, designers and persons with experiences in diverse projects.

If a breakthrough innovation is searched, most often the knowledge of the project group is not sufficient. The search for analogies can be expanded following two general strategies: search via people ( $\rightarrow$ networking) and search via databases.

In a network search the knowledge space expands through contacts to people that lead to other people and so on. As described, this method can also be used to identify lead users and analogue experts. The networking starts within the company: Each member of the project team has to talk to as many people in the company as possible about the problem to solve.

A database search can be based on several sources. Company intranet or special knowledge-management systems can help to access internal knowledge of the company. As one external source for analogies the internet can be used. In the hernia project we experienced that attractive analogue fields can be easily identified and explored by an internet keyword search. To start such a process, keywords are needed that derive from the problem definition. In this case, we searched for example after "closure of holes". Many interesting analogies were found, for example from other surgical fields like heart surgery or the fastening industry in general. While evaluating hits of the keyword-search usually other keywords appeared. Therefore the knowledge horizon broadens continuously through this process. However, the search can be strenuous as there will appear lots of not relevant hits that have to be sorted out. The advantages of an internet search - cheap access, huge search space have to be weighed against its disadvantages: Sources might not be reliable and the search can be inefficient. Other external sources for analogies are special databases, for example TRIZ-databases or biology-databases.

Which strategy a project-team should choose depends on the nature of the problem, how well the problem is defined or rather understood and the culture of the company. In order to search effectively in databases the problem has to be well understood and defined. Databases can be very inefficient, if you do not know what you are looking for. (Hargadon, 2002) Besides, databases can only contain explicit knowledge. Therefore, a search in databases excludes the tacit knowledge of the developers. In parallel, an effective network-search requires an open 
culture of information sharing in the company. Besides, this kind of search does not systematically scan the whole search space making it possible to overlook analogue solutions.

Of course, both general search strategies can also be combined. A change between the network and the database approach might be appropriate if the problem definition changes. For example, a project team that started with the networking approach, because the problem was only vaguely defined, can change to a database search if the problem becomes more concrete along the project.

And finally, if a company does not have the capacity or expertise for the search it can also outsource this task to special knowledge broker companies - for example design or consulting firms. (Hargadon 2002; 2003)

\subsection{Verification and evaluation}

The retrieved analogies need to be assessed. First, the analogy has to be verified: Is the analogue system accurately understood? Are the relevant functions and structures identified? This is very important as a wrong or misleading analogy can impede to find the right solution. Especially in bionics a thorough understanding of the biological system is important. For instance, an example of an invalidly drawn analogy was the attempt of men to fly by attaching bird-like wings to their arms.

After its verification, the analogy has to be evaluated regarding its transferability to the original problem. An analogy can be transferred on different levels: ${ }^{10}$

1. direct transfer of an existing technology into a new context,

2. transfer of structure,

3. partial transfer of functional principles, and

4. use of an analogy as idea stimulus.

The appropriate degree of transfer depends on the requirements of the problem solution. For example, in the hernia device project the partial transfer of functional principles and the transfer of structures from analogies was possible and led to the development of prototypes. On the other hand, a direct transfer of an existing technology from a different field was unlikely to succeed, because of high safety standards and extensive licensing procedures in the medical field.

And finally, technical success factors as well as commercial success factors need to be considered. Evaluation criteria can be the expected acceptance in the market, restrictions of the environment, time for development, costs of development, and costs of production etc. In order to avoid resistance within the company competences and culture of the company have to be considered.

The whole process of a systematic search for analogies is shown in figure 1. Subsequent to the search for analogies the development of promising concepts into new products has to be assured.

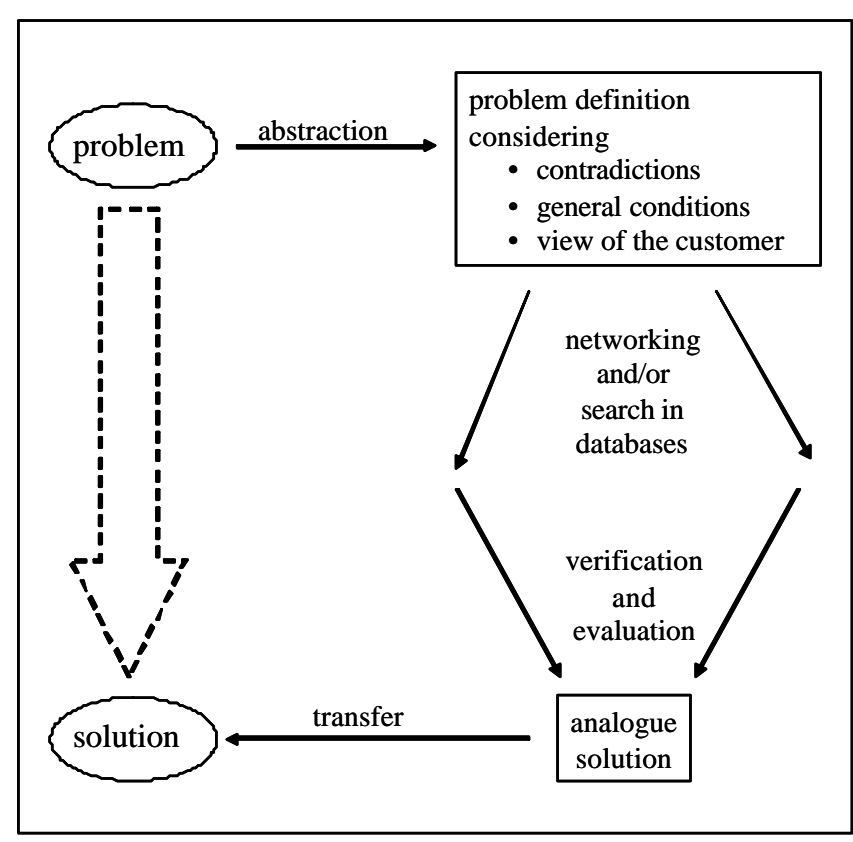

Figure 1: Systematic search for analogies

\section{Organizational conditions fostering the retrieval and application of analogies}

Breakthrough innovations are often generated by linking otherwise separated fields. (Hargadon, 2002) Especially far analogies bear the potential for high creativity (see section 2). As knowledge about analogue fields is one premise to successfully find and transfer analogies, the development team has to be able to access a wide knowledge space. Recombining interdisciplinary knowledge from diverse sources into an innovative solution is a key qualification of a successful development team.

Access to and exchange of interdisciplinary knowledge is often difficult or not possible. The social world can be described as fragmented - separated small worlds exist that hardly interact. Characteristically, strong ties exist within these communities and weak ties between them. Therefore knowledge flows rapidly and undisturbed within, but hardly in between these worlds. (Di Maggio 1997, Hargadon 2002) For example, networks of practice, although they encourage the internal flow of knowledge, show a tendency to constrain knowledge transfer across networks. (Swan et al., 2002) Functional areas in a company often resemble communities of practice. Empirical research indicates that direct cooperation between members of different functional areas of a company is the exception rather than the rule in innovation projects. This failure can be explained by the fact that in every organization the functional areas develop particular subcultures or "thought worlds" that are often not aligned with each other. (Schein, 1996, Dougherty, 1992) 
One way to facilitate the access and exchange of interdisciplinary knowledge is the building of interdisciplinary teams. According to the theory of absorptive capacity an "organization needs prior related knowledge to assimilate and use new knowledge." (Cohen and Levinthal, 1990, p.129) If an individual has diverse knowledge, the likeliness increases that incoming information will relate to already known things. Besides, diverse knowledge enables an individual to make novel associations and linkages which is important for creativity and innovation. This relation between knowledge diversity and creativity can not only be observed on the individual level but also on the organizational level. If the actors in an organization provide specialized knowledge from different areas, they will be able to tap into diverse external knowledge sources. Thus, diverse knowledge within the organization fosters its absorptive capacity. (Cohen and Levinthal, 1990) Besides, bringing together persons, that have a different background concerning their education and experiences, increases the knowledge space from which recombining innovations can be drawn. (Geschka and Reibnitz, 1983)

In addition, it is important how a company cultivates knowledge sharing. On the one hand, knowledge management systems based on intranet and databases can be established to foster knowledge transfer. However, databases can only transfer explicit knowledge. And if mechanisms for sharing knowledge like the intranet are implemented too drastically creativity and entrepreneurial drive are narrowed down. (Ali, 2001) Especially in creative tasks face-to-face contact and informal communication as for example in brainstorming sessions - are important to exchange tacit knowledge. For instance Persaud et al. show the importance of face-to-face communication in R\&D projects. (Persaud et al., 2001) Concerning the knowledge management a compromise has to be made between administrative concerns and creative dynamism.

Someone who is familiar with otherwise separated domains can act as a knowledge broker and transfer a solution from one domain to another. Whole companies, for example the design company IDEO, act as knowledge brokers. But knowledge brokers can also exist within a big diversified company linking separated groups or business fields and transferring ideas within the company. (Hargadon, 2002; 2003) "A firm needs both specialists to carry out specialised tasks and generalists to tie the different islands of knowledge together, creating a seamless whole." (Ali, 2001, p.339) It is not only critical to have and share substantive, technical knowledge, but also to know where relevant expert knowledge lies within and outside the organization. (Cohen and Levinthal, 1990) Therefore, a company is likely to achieve positive effects either by integrating persons that are capable of knowledge brokering into the development team or by establishing a special knowledge broker unit that transfers solutions across projects and fields within the company. Besides, Koberg et al. suggest that intrafirm linkages, for example cross project communication and the mixing of old and new team members, can increase the innovation potential of a company (Koberg et al., 2003).

Furthermore, management should promote access to external knowledge. Engineers can broaden their horizon by looking at other fields than their expert-field, for example by attending multiple-industry-spanning research groups and conferences or by engaging in other fields regularly. A culture needs to be established that is rewarding to those activities. And finally, people can be trained in analogical thinking, for example with a combination of a multimedia-training and workshops. (Vohle, 2004) Overall, adapting motivation and incentive systems can reinforce the effective use of far analogies in the front end of innovation.

To sum it up, positive effects on the use of analogies for breakthrough innovation can be expected by fostering interdisciplinarity within the organization. In addition, the cultivation of expert groups that are linked by knowledge brokers seems to be a success factor. If everyone tries to know everything in the company knowledge gaps as potential for innovation get lost. Besides, separated communities of practice that do not interact hinder the access to analogies and therefore to innovation as well. And finally, face-to-face communication is important to link separated groups and cannot be substituted by technologies like the intranet.

\section{Conclusion}

Analogies play an important part in the front end of product innovation. The probability to achieve a breakthrough innovation seems to increases with the distance of the analogy used. After abstracting the problem analogies can be searched in databases or via networking. Existing methods as TRIZ, bionics and the lead user approach can be incorporated in this process. Retrieved analogies need to be verified and evaluated. The use of analogies can be fostered by organizational mechanisms. Very important seems to be an interdisciplinary team, a culture of information sharing and the systematic assignment of knowledge brokers.

Although we concentrate here on the development of breakthrough innovations, a systematic search for analogies can also be useful with incremental innovations. And finally, in this paper we only look at the front end of the innovation process ending with the development of a first product concept. Of course, it is also important to assure the implementation of these concepts into breakthrough products. 


\section{References}

Ali, Y. (2001) The intranet and the management of making and using skills, Journal of Knowledge Management, 5, 4, 338348.

Bappert, R., Benner, S., Häcker, B. and Kern, U. (1998) Bionik, Zukunfts-Technik lernt von der Natur, Mannheim: Landesmuseum für Technik und Arbeit Mannheim.

Baxter, M. (1995) Product Design: A practical guide to systematic methods of new product development, London: Chapman \& Hall.

Birch, H. G. and Rabinowitz, H. J. (1951) The negative effect of previous experience on productive thinking, Journal of Experimental Psychology, 47, 2, 121-125.

Blanchette, I. and Dunbar, K. (2000) How Analogies Are Generated: The Roles of Structural and Superficial Similarity, Memory \& Cognition, 28, 1, 108-124.

Cohen, W. M. and Levinthal, D. A. (1990) Absorptive capacity: A new perspective on learning and innovation, Administrative Science Quarterly, 35, 1, 128-152.

Dahl, D. W. and Moreau, P. (2002) The influence and value of analogical thinking during new product ideation, Journal of Marketing Research, 34, 1, 47-60.

DiMaggio, P. (1997) Culture and cognition, Annual Review of Sociology, 23, 263-287.

Dougherty, D. (1992) Interpretive barriers to successful product innovation in large firms, Organization Science, 3, 2, 179-202.

Fiske, S. T. and Taylor, S. E. (1991) Social cognition, New York: Random House.

Gentner, D. (1989) The mechanisms of analogical learning. In Vosniadou, S. and Ortony, A. (Eds) Similarity and analogical reasoning, Cambridge: Cambridge University Press, pp. 199241.

Geschka, H. and Reibnitz, U. v. (1983) Vademecum der Ideenfindung : Eine Anleitung zum Arbeiten mit Methoden der Ideenfindung, Frankfurt a. M.: Batelle-Institut.

Gick, M. L. and Holyoak, K. J. (1980) Analogical Problem Solving, Cognitive Psychology, 12, 3, 306-355.

Gordon, W. J. J. (1961) Synectics: The development of creative capacity, New York: Harper \& Row.

Hargadon, A. (2002) Brokering knowledge : linking learning and innovation, Research in organizational behaviour, 24, 41-85.

Hargadon, A. (2003) How breakthroughs happen : the surprising truth about how companies innovate, Boston, Massachusetts: Harvard Business School Press.

Herstatt, C. and Geschka, H. (2002) Need Assessment in Practice - Theory, Methods and Experiences, International Journal of Entrepreneurship and Innovation Management, 2, 6.

Herstatt, C. and Lettl, C. (2004) Management of 'technology push' development projects, International Journal of Technology Management, 27, 2/3, 155-175.

Hill, B. (1993) Bionik - notwendiges Element im Konstruktionsprozeß, Konstruktion, 45, 283-287.

Hill, B. (1999) Naturorientierte Lösungsfindung : Entwickeln und Konstruieren von biologischen Vorbildern, RenningenMalmsheim: expert-Verlag.

Hill, B. (2004) In First International Industrial Conference Bionik2004 (Eds, Boblan, I. and Bannasch, R.) VDI, Hannover, Germany.

Holyoak, K. J. and Thagard, P. (1995) Mental leaps : analogy in creative thought, Cambridge: MIT Press.
Johnson-Laird, P. N. (1989) Analogy and the exercise of creativity. In Vosniadou, S. and Ortony, A. (Eds) Similarity and analogical reasoning, Cambridge: Cambridge University Press, pp. 313-331.

Keane, M. T. (1988) Analogical problem solving, Chichester u.a.: Horwood u.a.

Kelley, T. (2001) The Art of Innovation, New York: Doubleday.

Koberg, C. S., Detienne, D. R. and Heppard, K. A. (2003) An empirical test of environmental, organizational, and process factors affecting incremental and radical innovation, Journal of High Technology Management Research, 14, 1, 21-45.

Lettl, C. (2004) Die Rolle von Anwendern bei hochgradigen Innovationen : Eine explorative Fallstudienanalyse in der Medizintechnik, Wiesbaden: Deutscher Universitäts-Verlag.

Leonard, D. and Rayport, J. F. (1997) Spark innovation through emphatic design, Havard Business Review, 75, 6, 102-113.

Nachtigall, W. (1998) Bionik : Grundlagen und Beispiele für Ingenieure und Naturwissenschaftler, Berlin; Heidelber; New York: Springer.

Perkins, D. N. (1992) The Topography of Invention. In Weber, R. J. and Perkins, D. N. (Eds) Inventive Minds : Creativity in Technology, New York: Oxford University Press, pp. 238250.

Persaud, A., Kumar, U. and Kumar, V. (2001) Harnessing scientific and technological knowledge for the rapid deployment of global innovations, Engineering Management Journal, 13, 1, 12-18.

Reeves, L. M. and Weisberg, R. W. (1994) The role of content and abstract information in analogical transfer, Psychological Bulletin, 115, 3, 381-400.

Rummel, G. (2004) In First International Industrial Conference Bionik2004 (Eds, Boblan, I. and Bannasch, R.) VDI, Hannover, Germany.

Schein, E. H. (1996) Three cultures of management: The key to organizational learning, Sloan Management Review, Fall, 9-20.

Simon, H. (1957) Administrative behavior, New York: Macmillan.

Simon, H. (1982) Models of bounded rationality, Cambridge, MA: MIT Press.

Simon, H. (1996) Bounded rationality. In Eatwell, J. e. a. (Eds) The New Palgrave, London: Macmillan.

Squires, S. and Byrne, B. (Eds) (2002) Creating breakthrough ideas : the collaboration of anthropologists and designers in the product development process, Bergin \& Garvey, Westport, Connecticut.

Sutton, R. I. and Hargadon, A. (1996) Brainstorming groups in context: effectiveness in a product design firm, Administrative Science Quaterly, 41, 4, 685-718.

Swan, J., Scarbrough, H. and Robertson, M. (2002) The construction of 'communities of practice' in the management of innovation, Management Learning, 33, 4, 477-496.

Terninko, J., Zusman, A. and Zlotin, B. (1998) Systematic innovation: an introduction to TRIZ, Boca Raton et al: St. Lucie Press.

VanGundy, A. B. (1981) Techniques of Structured Problem Solving, New York: Van Nostrand Reinhold Company.

Vincent, J. F. V. and Mann, D. L. (2002) Systematic technology transfer from biology to engineering, Phil. Trans. R. Soc. Lond. A, 360, 159-173.

Vohle, F. (2004) "Stellen Sie sich das so ähnlich vor wie...!" Analogien als Denk- und Sprachbrücken in heterogenen Teams. In Wyssusek, B. (Ed.) Wissensmanagement komplex, Berlin: Erich Schmidt Verlag, pp. 189-206.

von Hippel, E. (1988) The sources of innovation, New York: Oxford University Press. 
von Hippel, E., Thomke, S. and Sonnack, M. (1999) Creating breakthroughs at 3M, Harvard Business Review, 77, 5, 47.

Vosniadou, S. (1989) Analogical reasoning as a mechanism in knowledge acquisition: a developmental perspective. In
Vosniadou, S. and Ortony, A. (Eds) Similarity and analogical reasoning, Cambridge: Cambridge University Press, pp. 413437.

\footnotetext{
${ }^{1}$ Schemata are explained for example in Fiske and Taylor (1991)

${ }^{2}$ This was the case in the development of the sport shoe "Nike SHOX".

${ }^{3}$ The antilock breaking system was first developed for military aircraft.

${ }^{4}$ Genrich Altschuller was born 1926 in the former Soviet Union and died 1998.

${ }^{5}$ TRIZ can also be applied without software support.

${ }^{6}$ At the bionic conference Bionik2004 in Hannover, Prof. Hill stated that he has collected so far about 2000 solution principles.

${ }^{7}$ Examples of bionic textbooks are Nachtigall (1998) and Hill (1999).

${ }^{8}$ q.v. www.bionicsolutions.de

${ }^{9}$ www.bath.ac.uk/mech-eng/biomimetics/Projects.htm

${ }^{10}$ This classification is derived from different levels of transfer in bionics according to Hill (1999).
} 